\title{
ENTREVISTA
}

\section{A VIDA COMO POTÊNCIA ENTREVISTA COM LUMA NOGUEIRA DE ANDRADE ${ }^{1}$}

Felipe Bruno Martins Fernandes, Universidade Federal da Bahia Igor Leonardo de Santana Torres, Universidade Federal da Bahia

Felipe: Hoje é 11 de dezembro de 2017, às 19h46min, em Salvador. Estou aqui com a Professora Doutora Luma Nogueira de Andrade que veio para a reunião do Laboratório Interdisciplinar de Políticas LGBT (LABI), coordenado pelo grupo de pesquisa Diadorim/UNEB. Aproveitando sua vinda, faremos essa primeira entrevista para a Revista Brasileira de Estudos da Homocultura (REBEH). Boa noite, Luma!

Luma: Boa noite.

Felipe: Queria que você começasse falando um pouco da sua trajetória e também da sua época na escola.

Luma: Sou filha de agricultores analfabetos, pai e mãe, que vêm do interior do estado do Ceará, onde, na verdade, não tinham oportunidades e também não viam a educação como uma forma de superação das dificuldades as quais vivenciávamos. Com o passar do tempo, minha mãe se apropriou mais de informações, e me incentivou os estudos. Aí, eu passei a frequentar a escola.

Felipe: Com quantos anos?

Luma: não me recordo ao certo com qual idade comecei a frequentar a escola. E sempre fui muito feminina, tinha um cabelinho grande, e era muito confundida com uma menina. Inclusive, na rua, quando estava com meus pais, isso causava muito constrangimento; principalmente para meu pai porque as pessoas diziam "é essa sua filha, essa sua meninazinha?". Pra ele essas situações eram bastante constrangedoras, e isso também me rendia algumas indagações em casa, algumas tentativas de mudança de postura, através de ações violentas.

A escola chegou como uma linha de fuga. Na verdade, eu começo a me dedicar mais aos estudos e me afastar das brincadeiras, porque tinha momentos em que a brincadeira era muito difícil, por conta de que eu gostava de brincar com as meninas, pois me identificava com elas. Eu não gostava das brincadeiras dos meninos, eu as achava violentas. Não estou querendo tratar como algo essencialista. Eu não estou querendo que se pense dessa forma. Mas, na verdade, eu me aproximava mais dessa subjetividade que existia nas meninas, que não produziam tanta violência nas

${ }^{1}$ Revisão de Carlos Eduardo Bezerra \& Frederico Fagundes Soares. 
brincadeiras. Se eu fosse brincar com aquelas brincadeiras dos meninos, eu sempre era agredida, porque sempre era violentada. Então, assim, eu me identificava mais com as meninas.

Felipe: você tem irmãos?

Luma: eu tenho uma irmã. E minha irmã, inclusive, ia me deixar na escola porque ela também tinha medo de eu ser violentada. Então, ela ia me deixar e às vezes ainda ficava lá até terminar a aula, para poder voltar comigo. Porque eu não conseguia ter muita mobilidade nas brincadeiras, na hora do intervalo, nas interações, por conta da violência que existia. Uma violência que não era só comigo, era também com as outras crianças, mas era uma violência tida como uma brincadeira. Tudo era considerado uma brincadeira. E o fato de estar mais próxima das meninas, talvez isso me rendesse ainda mais. Na verdade, me rendia muito mais agressões, por conta de que não aceitavam que eu estivesse com as meninas, e não com os meninos; que eu gostasse de brincadeiras que não fossem tão violentas, enquanto os meninos gostavam de brincadeiras que fossem mais bruscas. Não querendo produzir o essencialismo, mais uma vez, pois não é essa a ideia. Na verdade, foi essa singularidade que ocorreu.

Felipe: Para além da violência, você gostava da escola?

Luma: eu gostava de aprender. Eu encontrei nos estudos uma alternativa de me centrar com o apoio da família. Principalmente em relação a minha mãe, porque meu pai não me dava muito incentivo, não via os estudos como algo relevante. Mas minha mãe sim e, com seu incentivo, fui me dedicando. Então sempre que me colocavam numa situação de "ah, cadê a namorada?", "com quem você tá paquerando?", às vezes até minha mãe entrava e dizia “não, mas ainda é muito cedo, está se dedicando aos estudos", "está buscando outra coisa". Então, eu usei isso como estratégia. Ela, talvez, usou como uma justificativa.

Também busquei religiões. Eu tinha avós evangélicas - minha mãe também foi evangélica - e isso também me conduziu para a questão da religiosidade. Tive um período em que vivenciei tanto a religião evangélica, como a católica e outras religiões, posteriormente. Mas, inicialmente, a religião católica e a evangélica, por conta da minha família. A religião era utilizada como uma linha de fuga, para eu poder não ser enquadrada dentro dessa postura negativa da diversidade.

E a escola, ela passou a ser algo importante para a minha vida, que era vivida para estudar. Talvez, por isso, eu sempre me destacava. E quando estudei no turno da manhã ou da tarde tive contato com pessoas jovens assim como eu e tudo era mais difícil, pois as brincadeiras eram pesadas. E eu percebi que se continuasse estudando naqueles turnos de crianças e adolescentes, eu não ia conseguir ter sucesso, porque havia uma tentativa de boicote o tempo todo, de violência, de repressão. Eu não podia ir para o intervalo - e como o intervalo era o momento da distribuição da merenda escolar -, acabava ficando sem esse direito. Eu ficava dentro da sala de aula, porque as 
vezes que saía, que ia interagir com as meninas no intervalo, acabava sofrendo violência. Então eu ficava mais onde? Na sala de aula. Não tinha o direito ao intervalo, nem a ir merendar, tampouco tinha o direito de utilizar o banheiro, porque os meninos não aceitavam. Se eu entrasse lá, eles me violentavam. E as meninas jamais aceitaram. Estou relatando algo de uma época em que as situações de gênero e sexualidade eram ainda mais complicadas, não se tinha nenhuma discussão, resoluções, portarias ou mesmo pessoas dentro da escola defendendo essas questões. Era tudo muito incipiente.

Felipe: e você já era Luma?

Luma: sim, já. Com a singularidade feminina já presente no meu corpo. Porque o objeto dessa violência é exatamente essa feminilidade que se julga como subordinada. Principalmente, porque, em nossa sociedade, se rejeita a possibilidade de alguém ter um pênis e performar, viver e existir de forma feminina. Então evitam e negam totalmente, porque não conseguem incorporar esses padrões. Isso é de outra ordem e bagunça muito a cabeça das pessoas, que não conseguem compreender, porque elas vêm de uma espécie de adestramento. E nós mesmas, às vezes, não conseguíamos entender. Principalmente em uma época em que não se falava sobre essas questões, não se tinha produções mais substanciais que chegassem a nós ou à população de forma geral, como hoje está chegando - lentamente, mas já um pouco mais. Então era uma situação ainda mais complexa na época, porque faltava solidariedade das pessoas, às vezes de compreender, de entender, e havia sempre uma tentativa de enquadramento para o pensamento heteronormativo. Sempre se enquadrar ao que se acha que é o correto. A escola tinha também o papel de fazer isso, de adestrar esse corpo para uma sociedade que se deseja, a sociedade desejada. Então não cabe isso. Várias vezes eu fui violentada, e gestores e professores achavam que isso estava correto, porque aquela punição que eu sofria, aquela violência que era exercida sobre o meu corpo, era algo que servia como "lição" para eu aprender a me "comportar".

Felipe: então você se identifica como uma pessoa trans.

Luma: Travesti. Por que politicamente enquanto travesti? Eu tenho consciência, lógico, como uma estudiosa da filosofia da diferença, de vários autores como Deleuze, Foucault, enfim, vários teóricos que vêm nessa linha, que nós temos possibilidades múltiplas de ser o que a gente quiser. $\mathrm{Na}$ verdade, as palavras que são criadas e os conceitos que são criados, produzidos, eles não dão conta da complexidade das coisas e, principalmente, das pessoas. Então, as pessoas têm uma complexidade extrema e as palavras não conseguem engessar esses comportamentos. E a ideia das palavras é exatamente essa, de organizar as pessoas, colocá-las dentro de um ritmo que é esperado por essa construção social tradicional.

Assim, tenho várias possibilidades de ser, eu posso ser bi, tri, diversas possibilidades. E eu não vejo isso como uma anormalidade, são desejos. E desejos, prazeres podem acontecer podem acontecer de 
diversas formas, em diversos lugares, com diversos corpos, e mesmo independente dos corpos: os corpos podem ter vagina, os corpos podem ter pênis, os corpos podem ter pênis e vaginas, os corpos podem ter seios, podem não ter seios. Você pode ter prazer com diversas formas de corpos, porque temos prazeres até sozinhos com a nossa própria mão. A mão dá a possibilidade de sentir prazer, imagine com outros corpos, com outros toques, com outras possibilidades?

Por isso que eu me coloco enquanto travesti, por conta de uma história, de tentar tirar esse padrão de que travesti é uma pessoa que não tem qualificação, que é marginal, que não tem como ser uma professora, uma doutora, uma médica, uma advogada. Quer dizer, nós somos pessoas como quaisquer outras e nós temos a possibilidade de chegar em qualquer lugar, como qualquer outra pessoa. Lógico que não podemos dizer que isso ocorre de uma forma igual. Logicamente, para uma travesti ser doutora, ser uma médica, uma advogada, se ela faz o percurso desde o início com essa singularidade, ela vai ter muito mais dificuldade do que uma pessoa que não vivenciou essa diferença desde o início.

Por conta disso, nós temos várias pessoas travestis, transexuais e até homossexuais afeminados que são colocados para fora de casa, não têm direito à família, não têm direito à escola, não têm direito à religião, não têm direito ao trabalho - um trabalho que seja reconhecido pela sociedade. E aí resta o quê? O corpo. O corpo como a única forma de subsistência. O corpo é o que vai dar a sobrevivência do indivíduo, e aí o que ocorre? Ocorre o processo de prostituição que é tão questionado pela sociedade, mas a própria sociedade não problematiza que isso é uma consequência da ausência de possibilidades, muitas vezes. Inclusive pelo histórico das pessoas travestis no Brasil, porque houve um momento em que nos denominávamos apenas como travestis. Esse era o termo que existia na época, mesmo sendo considerado negativo. Agora nós vivenciamos outros termos e outras possibilidades, como "trans". Mas isso é algo que surge de outro contexto, de outra realidade cultural, social, diferente da nossa, e que passa a ser incorporado na nossa realidade. E isso, de certa forma, pode induzir ainda mais à negação histórica da existência travesti. Por exemplo, em muitos lugares em que me apresento, as pessoas, mesmo sabendo da minha posição, me anunciam como transexual. Na primeira oportunidade, realizo a correção, informando que sou travesti.

Felipe: então a gente poderia dizer que travesti é uma categoria mais decolonial do que outras, uma vez que travesti não é uma categoria conjurada a partir de uma colonialidade do saber, de um pensamento eurocêntrico?

Luma: com certeza, porque é um termo, inclusive, utilizado para depreciá-las, principalmente no passado. Então dizer "ah, é travesti” é tradicionalmente visto como algo ruim, marginal, não aceito pela sociedade tradicional - inclusive, motivo de prisões. A própria existência da travesti é uma afronta, é inaceitável dentro de um contexto social conservador. E aí vem a questão das ruas como a possibilidade de sobrevivência, pelo que já foi relatado. Esse corpos nus que aparecem - nus não só de vestes, mas nus também de direitos, de possibilidades - e que tentam subsistir dentro quase do nada, para poder resistir, poder sobreviver. Então nós não podemos hoje chegar onde chegamos - 
eu chegar onde eu cheguei -, e, simplesmente, esquecer que, para estar onde estou, várias outras estiveram na linha de resistência, de enfrentamento. E que essas pessoas deram a vida para poder estarmos onde nós estamos hoje. Uma forma de dar um retorno, para a transformação da sociedade, é dizer "olha, essas pessoas que lá no passado eram vistas como más, eram vistas como perversas, eram vistas como atentados ao pudor, elas não eram nada disso que se diziam sobre elas". Na verdade, eram formas de sobrevivência e de resistência para poder existir.

Felipe: então nós podemos pensar os estudos trans hoje na universidade ou os estudos travestis como uma forma de reparação histórica ou de ação afirmativa, não?

Luma: é uma forma de positivar a injustiça cometida com essas pessoas. É uma alternativa, inclusive, de empoderá-las mesmo. Que elas possam ser elas mesmas, que elas possam ser travestis. Que elas, que vivenciaram a travestilidade no passado, inclusive se autoidentificavam como travestis, não tenham hoje a vergonha de dizer que foram travestis; porque é motivo até de ter orgulho. Porque elas estiveram à frente, elas foram máquinas de guerra, em um contexto que era cruel. Estamos nos aproximando, mais uma vez, de um momento muito parecido de crueldade, de não aceitar, de uma rejeição extrema, de uma linha de negação muito forte de nossa existência. Principalmente agora que nós estamos ocupando outros lugares.

Eu não estou aqui querendo dizer que ser travesti é melhor que ser trans ou que ser trans é melhor que ser travesti. A ideia não é essa. A ideia é construirmos uma linha histórica de conhecimento sem menosprezar a existência das que nos antecederam, sem marginalizá-las, mas respeitando a forma como se autonomeavam. Isso é uma coisa importante que podemos aprender com o movimento negro, pois o que o movimento negro faz? Fanon nos ensina que, no passado, não se utilizava nem o termo negro, que era uma ofensa. Era a mesma coisa em relação às travestis: travesti era uma ofensa, visto como uma ofensa. Então no passado não se utilizava esse termo - negro. Eram homens de cor, mulheres de cor, uma forma de não chamar de negro, porque negro era um termo ofensivo. Assim, temos a possibilidade de aprender com o movimento negro e dizer o seguinte "olha, nós somos travestis, e somos travestis professoras, travestis doutoras; porque hoje nós tivemos possibilidades que nossas colegas não tiveram no passado".

Ser travesti ou ser transexual não perpassa por uma questão de genitália, porque aí seria da mesma ordem do que criticamos com a questão do ser homem, do ser mulher. Não é uma questão de genitália, é uma construção dentro da sociedade. Ser travesti e ser transexual é uma construção e uma autoidentificação independente de se ter genitália A ou se ter genitália B, ou mesmo de se fazer isso ou aquilo com a genitália, o que não vem ao caso. O que importa quando eu me autoidentifico politicamente enquanto travesti não é que eu estou centrada em uma identidade fixa - porque eu sei das possibilidades que eu tenho, que eu pratico -, mas é dizer que é possível positivar esse termo, reconhecendo a existência das que nos antecederam e o enfrentamento que elas tiveram. Hoje ainda existe uma tentativa de desqualificação interna: "ah, eu sou trans, e travesti é um homem de peito" algumas costumam pensar dessa forma. Então a ideia não é essa: colocar as pessoas trans contra as 
pessoas travestis. A ideia é dizer que as pessoas podem se autoidentificar como elas quiserem, porque esses termos são construções e cada um se posiciona politicamente da forma como deseja. $\mathrm{O}$ importante é ter a consciência que nós temos múltiplas possibilidades, inclusive uma possibilidade de trazer contribuições históricas para o processo de transformação da sociedade.

Felipe: você se vê nesse grupo "trans"? Você é uma delas?

Luma: eu estou presente dentro desse contexto, mas com uma consciência muito clara de que eu tenho trânsito, de que nós temos trânsito, que nós temos diversas outras possibilidades. Tem momento que eu me enquadro dentro de um determinado contexto como travesti, tem momento que eu me enquadro dentro de um contexto como trans. Eu posso ser tudo. Então, assim, não são os termos e conceitos que vão dar conta da complexidade das minhas possibilidades de ser. Precisamos ver que há um movimento político por trás disso, porque a pessoa que fez a redesignação sexual pode se autoidentificar como travesti e isso não a diminui em nada.

Felipe: eu tenho amigas que são assim.

Luma: isso não as diminui em nada, isso não as desqualifica em nada. “Ah, é porque é um termo que vai nos aproximar mais do que se entende socialmente como mulher", no pensamento mais tradicional. Isso me aproximaria, em tese, mais do desejado. Mas precisamos parar com isso, porque não existe essa perfeição. Nós estamos o tempo todo em construção e reconstrução, numa tentativa de enquadramento de algo que é impossível. É o fascismo do corpo: eu entro numa onda de um fascismo de querer esse corpo ideal, e na verdade, esse corpo é apenas um imaginário, ele é algo idealizado. E eu tento me aproximar o tempo todo desse - que eu utilizo muito, inclusive, um termo - mulheramento, que é uma tentativa também de melhoramento. Como se à medida que você se aproximasse desse mulheramento, mais espaço você tivesse e maior qualificação você passasse a ter dentro da sociedade e dos lugares, porque você está mais próxima daquilo que você deseja. Até criaram um termo, passabilidade, que você teria em maior ou menor grau. O que é essa passabilidade? É você se enquadrar direitinho no que a sociedade espera. Você passou, então se você passou, se você tem essa tal dessa passabilidade, que ruptura você traz? Que mudança você traz? Que possibilidades de outros corpos você traz? Nenhuma, você se enquadrou. Então precisamos entender que há a necessidade de ter corpos que vão confrontar esse modelo ideal. Por isso é importante não criar essa coisa de regras, de conceitos fechados: "ah, travesti é isso, transexual é aquilo". São autoidentificações, porque as pessoas se autoidentificam, e aí algumas vão achar mesmo que devem utilizar determinados termos, porque é mais cômodo, é mais interessante, é mais aceito; e outras vão dizer "não, vamos por uma linha de resistência. Olha, não, eu sou assim, mas eu vou me identificar com esse outro termo, que ele me soa como uma possibilidade outra" até de afastamento desse mulheramento, de uma tentativa de mulheramento - que é também uma forma de negar esse corpo idealizado. Por que eu tenho que me enquadrar dentro desse corpo? Para 
eu ser aceita no gênero feminino, eu tenho que estar totalmente enquadrada. É isso que acontece, por exemplo, quando solicitamos a mudança de nome.

Felipe: e você mudou o nome, não mudou?

Luma: mudei o nome, sim. Sem a questão de ter que passar por cirurgias ou algo parecido. Sou muito bem resolvida nesse campo. Então eu tenho minha genitália masculina, mas ela não define o meu gênero em hipótese alguma. Eu sou uma mulher com pênis, eu sou uma trans com pênis, eu sou uma travesti com pênis, eu sou várias possibilidades de ser. Mas o importante é o quê? É afrontar as normas, é dar voz também aos corpos que produzem um enfrentamento a esse modelo, a esse mulheramento. É dizer, "eu posso ser uma trans que não atende a esse padrão de trans que está sendo dado". Eu sou uma travesti que também não atende a esse padrão e que pode embaralhar tudo, por isso, assim, os conceitos, nenhum deles dá conta. A nossa realidade é muito mais complexa. E nós precisamos sair disso, ver as pessoas como possibilidades diversas e aceitar o que elas dizem sobre si.

Felipe: Te escutando sobre aceitar as pessoas nas possibilidades diversas, e o que elas têm a dizer sobre si, me lembrei que a primeira definição que você trouxe sobre você é que é "interiorana, filha de agricultores". Eu gostaria de te pedir que coloque o gênero em suspensão e me diga um pouco o que é ser do interior do Ceará, filha de agricultores, e o que essa posição trouxe para você se tornar essa docente que você é hoje.

Luma: com certeza, porque viemos do nada. Nasci no município de Morada Nova, Ceará. Assim, é sair de uma condição precária, uma vida muito precária, onde você olha para os lados e você não vê possibilidades. E você tem que criar as possibilidades, a possibilidade para poder sobreviver, para poder conseguir alguma coisa - até de se alimentar, de ter condições de adquirir o lápis, a caneta; algo que é tão simples para algumas pessoas. Quando você vem de um lugar e de um contexto familiar em que você está acostumado a não ter nada, você começa a buscar do nada possibilidades, e você encontra no nada possibilidades - e é daí que vem a criatividade. É muito importante essa questão de você sair do nada e buscar no nada possibilidades. Você vai ver o mundo de forma diferente, porque as pessoas vão dizer "isso aqui é assim". Para você que vem de uma situação do nada, você já vê aquilo como outra potência, o que outras pessoas não conseguem ver. E aí é onde você vai crescer, porque você vê do nada o potencial. É como ver a potência da vida. Você vê a vida precária e, nela, vê potência para sobrevivência. A sua criatividade é a única forma de encontrar a saída. E seu olhar vai ver coisas que outros olhares, que não vivenciaram o nada ou o quase nada, não conseguem visualizar. E aí a gente consegue, quando chega a ter outras possibilidades, se ver com maior potencial e consegue seguir o caminho ainda mais forte.

Então eu acho que sair do nada traz um potencial de criatividade muito grande, porque é como se fosse a potência da vida. Ela vai do nada. A vida te dá uma potência tão forte que você vai conseguir 
sobreviver a todas essas barreiras: a força da normatividade que tenta te retrair, que tenta te colocar: "olha aqui, você nasceu nesse lugar, você não tem possibilidade", "olha, você não tem nada", "olha, daqui você não vai sair, daqui você não vai crescer". Dessa experiência de uma situação de classe interseccionalizada com a questão de gênero e sexualidade, surge um potencial ainda maior de tentativa de resistência, de sobrevivência nesses lugares normativos; porque você vai passar a representar o não lugar, o não lugar da classe - de uma situação de classe baixa -, e outro lugar, também, que é a questão do não se enquadrar dentro de uma ordem de gênero, como previsto pela sociedade tradicional, conservadora. E aí, você vai sempre estar no meio de um não lugar. E você vai buscando, abrindo seus espaços de uma forma lenta, às vezes se assujeitando - por isso o nome do meu livro -, mas produzindo sempre aberturas.

Há momentos em que você se assujeita; há a necessidade de se assujeitar, porque é pesado e difícil, mas ao mesmo tempo em que você se assujeita, você consegue penetrar ainda mais o sistema. E aí, você vai possibilitando ter aberturas, posteriormente. É um processo lento, por isso que é tão diferente para alguém, que vem de camadas baixas e de uma identidade de gênero que vai contra os padrões tradicionais, chegar a um determinado lugar nessa sociedade, porque existe uma tentativa constante de boicote. As normas vão tentar o tempo todo te barrar, e se você for muito educadinha, adestradinha, dentro desse pensamento, você acaba incorporando tudo isso. Por isso, eu já encontrei, nas minhas andanças, várias travestis que, quando sabem da minha história, conhecem a minha trajetória de vida e de outras colegas, ficam se questionando "e é possível? É possível uma travesti ser professora?"; porque já incorporaram esse pensamento normativo, e aí não veem possibilidade de saída, de resistência. Não encontram o potencial da vida, porque já se entregaram às normas instituídas que não dão lugar para nós.

Felipe: Luma, desde que assisti ao filme do Vagner de Almeida, "Janaína Dutra: uma Dama de Ferro" (2011), sobre essa ativista também cearense e conhecendo a trajetória de grandes lideranças dos movimentos trans*, percebo que o interior é um lugar central para essas pessoas. Sabemos que há um etnocentrismo no movimento LGB de imaginar a capital como um grande paraíso para viver as sexualidades dissidentes. Temos o exemplo de Janaína Dutra, Keila Simpson, que veio do interior do Maranhão; Kátia Tapety, que é uma grande liderança no interior do Piauí e vários outros exemplos de pessoas que não vieram da capital, mas que tem hoje um lugar de liderança nos movimentos trans* e em outros movimentos sociais também. Hoje, como docente da UNILAB em Redenção, interior do Ceará, você vê essa universidade como uma potência?

Luma: com certeza, por conta do próprio lugar. A Universidade da Integração Internacional da Lusofonia Afro-Brasileira (UNILAB) foi pensada dentro de um contexto da diferença, que inclusive traz muito forte a questão do negro, porque é fruto também da luta do movimento negro, que conseguiu certa abertura no governo Lula, que atendeu à reivindicação histórica de criar uma universidade que possibilite essa integração do Brasil com os países do continente africano e pautando as relações Sul-Sul que antes eram totalmente esquecidas, pelo menos na gestão governamental. Essas parcerias não eram bem vistas, pois se dizia que não possibilitavam maiores lucros para o país. Devido a essa necessidade de outra postura, outra prática, em relação ao que o 
Brasil vivenciou com a multidão escravizada que foi trazida do continente africano, coube uma contribuição com aquele continente que deu grandes contribuições para o nosso país. É dentro deste contexto que surge a UNILAB com essa perspectiva da diferença. E nessa instituição fui aprovada como docente efetiva no ano de 2013 e passei a ser conhecida, além de primeira doutora travesti do Brasil, como a primeira docente travesti efetiva de uma universidade federal do país.

Felipe: que está no interior...

Luma: que está no interior, que tem um objetivo muito grande que é a interiorização e a internacionalização, que é um desafio muito grande alinhado a essa questão da diferença. Porque lá , 50\% dos estudantes são brasileiras e brasileiros e 50\% são africanos e africanas, que vêm de vários países da África, especificamente dos Países Africanos de Língua Oficial Portuguesa (PALOP). Assim, temos uma multiplicidade de culturas, de formas de viver, de se relacionar, interagindo ali naquele lugar. A própria UNILAB surge também como esse lugar de resistência, porque ela passa ainda mais a potencializar as pessoas que não tinham oportunidade de ter acesso à universidade. Então, às vezes, as pessoas costumam dizer - o próprio reitor que tivemos chegou a relatar - "a UNILAB está no lugar errado", porque a cidade não tem estrutura para receber a universidade. Ela não consegue atender à demanda que é necessária em termos de serviços, em termos de habitações, saneamento, enfim, todo o contexto.

Felipe: e você concorda com isso?

Luma: não concordo, porque a universidade está no lugar em que ela nunca esteve.

Felipe: na Avenida da Abolição.

Luma: na Avenida da Abolição, 3, no campus da Liberdade.

Felipe: em frente ao Museu da Cachaça!

Luma: exatamente. Então esse é um lugar em que a universidade tem que estar, pois é o lugar onde os filhos das trabalhadoras e dos trabalhadores estão. As pessoas que mais necessitam estão lá sem ter acesso muitas vezes a uma universidade na capital, porque dependeriam de mais recursos, de condições em termos de organização familiar - porque tem gente que trabalha, tem gente que tem filho(s) -, e isso exige uma dinâmica outra. Então a UNILAB está no lugar certo!

Agora a cidade tem que acompanhar o potencial que está chegando. Mas, em termos de conhecimento, está sendo fundamental, a qualificação dos profissionais que estão saindo da universidade é outra, inclusive eles já saem com análise crítica de, por exemplo, como a docência 
pode ser melhor quando se tem conhecimento. E na universidade se trabalha as questões da diferença. Nós temos várias disciplinas, como Gênero e Diversidade Sexual, que é obrigatória no curso de Pedagogia. Nós temos outros cursos que atendem essa diferença. Quando você trata da própria questão da história do negro e da negra no Brasil, do processo de escravização das pessoas negras, você passa a trazer outro conhecimento que nós não adquirimos nas universidades tradicionais pelas quais passamos.

Eu, pelo menos, venho de uma universidade tradicional e que outros e outras também não tiveram a oportunidade de ter acesso a esse outro conhecimento, outro olhar, a outra epistemologia, outra forma de pensamento e de saberes na universidade, porque a nós foi dado somente aquele pensamento eurocentrado, já de adestramento, reforçando todos os ideais das normas tradicionais que já estão postos na sociedade. Muitas vezes, a universidade só legitimava ainda mais o que a gente aprendia na família, na religião, enfim. Agora, lógico, nós temos em várias universidades, inclusive tradicionais, mudanças estruturais, epistemológicas, produzidas com a entrada de novos doutores ou então com os doutores que já existiam com outras perspectivas em pesquisa e extensão, que trazem o pensamento da filosofia da diferença. Porque é importante que a gente saiba: não é uma questão de universidade, é uma questão de pessoas. Então quem são as pessoas que estão nessas universidades? Porque a universidade são pessoas. Como essas pessoas pensam? O que elas trazem? Como elas estão desenvolvendo a formação dos futuros professores, dos futuros médicos, dos futuros advogados, dos futuros profissionais que irão atuar na sociedade, que passam por essa formação inicial? Então tudo vai depender também dessa massa de recursos humanos que está presente dentro da universidade. E aí, quem está entrando como docente nas universidades agora, novos doutores, em algum momento tiveram a oportunidade de trabalhar com essa possibilidade da filosofia da diferença, e quem não teve está buscando. Alguns até através do autodidatismo, através de cursos de formação, dos eventos que são realizados, acadêmicos, com as questões de gênero e diversidades sexuais, com as questões da diferença. E essas pessoas, que têm interesse em acompanhar esse processo de transformação da sociedade, estão buscando se atualizar quanto a esses saberes para poder produzir uma mudança de postura dentro do seu processo de atuação profissional.

Felipe: Algo que aprendo muito com você é sobre a gestão escolar. Qual o lugar da gestão escolar na sua carreira?

Luma: às vezes as pessoas até se assustam quando eu digo assim "eu estou atuando na disciplina de Estágio em Gestão Escolar" ou "eu estou atuando na disciplina de Fundamentos da Gestão Escolar". As pessoas olham, param e dizem "nossa, você ministrando essas disciplinas?". As pessoas sempre vão esperar que eu atue só com gênero, devido à minha pessoa e à minha qualificação, a competência de tratar especificamente da questão de gênero e diversidade sexual. Eu participei da construção do Plano Político Pedagógico (PPP) do curso de pedagogia da UNILAB e tive uma grande contribuição em poder aprovar no colegiado uma disciplina obrigatória que é 
"Educação, gênero e sexualidade nos países da integração". Eu estava ministrando inicialmente essa disciplina, mas com a entrada de novos pesquisadores, novas pesquisadoras, no nosso colegiado, eu vi pessoas com potencial para desenvolver muito bem o trabalho. Dentro do colegiado que eu participo, de Pedagogia, temos a professora Jacqueline da Silva Costa - que é uma mulher negra, feminista, que entende as questões de gênero e de diversidade sexual. Temos também o Carlos Eduardo Bezerra, nas Letras, a professora Violeta Maria de Siqueira, na Antropologia; Pedro Rosas Magrini, na Administração Pública; Francisco Vítor Macêdo Pereira, na Filosofia. Existem outras pessoas que também têm a possibilidade de contribuir, inclusive que não sejam do grupo das letrinhas LGBT. Pessoas que sejam inclusive héteros. Por que elas não podem, se elas têm potencial? Se percebemos isso nas suas produções, nos seus diálogos, nos seus discursos, por que elas não podem falar? Elas podem falar, sim.

Felipe: então, para você, não são apenas as pessoas trans* que podem falar de pessoas trans*? Não são apenas os gays que podem falar dos gays, e assim por diante?

Luma: não existe essa regra, não pode existir essa regra, porque aí nós estamos tratando de questões de pesquisa. Nós estamos dentro de um espaço acadêmico, onde nos aproximamos das realidades que nos interessam conhecer. Eu posso ser uma travesti, e, de repente, eu não estar interessada em nada com a questão travesti, em nada com a questão LGBT...

Felipe: aqui nós temos na Universidade Federal do Recôncavo da Bahia, a professora Fran Demétrio que é nutricionista e fez uma tese de excelência sobre nutrição num dos mais bem qualificados programas de saúde coletiva do país. Claro, não tem como a gente fugir das questões de gênero e sexualidades quando a gente ocupa uma vaga de docência, entretanto ela tem - para além da pesquisa sobre gênero e sexualidade, das intervenções dela - muitas contribuições no campo da nutrição que são super interessantes. Ela inclusive fala que os nutricionistas têm que aprender a lidar com a diversidade, porque no momento de fazer uma dieta para uma mulher trans ou uma travesti, as pessoas tratam o corpo simplesmente como se fosse um corpo masculino. Então eu estou achando super interessante o que você está falando, e por isso eu quis retomar essa questão da gestão escolar.

Luma: e aí o que acontece? Você pode estar totalmente deslocada, ainda assim tem a possibilidade de entrada do tema da diversidade. "Não, eu vou falar da nutrição, mas perpassando pela questão de gênero e diversidade sexual". Mas você pode ter pessoas trans que têm uma produção que não tem nada a ver com a diversidade. Isso vai desqualificar a pesquisa? Como vai desqualificar? Seria um essencialismo pensar que uma pessoa trans já nasce sabendo tudo sobre questões trans. Então eu vou falar do quê? Do que eu vivi? Não é isso. Então temos que entender qual é o lugar do pesquisador e da pesquisadora. Não é ter propriedade de um determinado conhecimento. Eu sou pesquisadora, eu posso pesquisar qualquer temática. Lógico que existem as dificuldades de inserção nos campos. Tem campos em que é mais fácil a inserção para uma pessoa travesti, tem campo em 
que é difícil e tem campo em que é quase impossível. E aí, a própria pesquisadora/pesquisador tem que ter consciência disso, nós temos que aprender, por exemplo, com Clifford Geertz, que há necessidade da aproximação, mas também do afastamento. Não é uma questão só de estar dentro. Pelo contrário, o fato de estar dentro pode ser extremamente perigoso.

Felipe: e nos cegar para várias questões.

Luma: exatamente. Exatamente o que Geertz chama atenção para a gente - um clássico nessa metodologia. Cuidado com o dentro, porque você está cego, você vem com todo o pensamento já construído. Você não faz a pesquisa porque você quer colocar no papel aquilo que você pensa sobre aquela questão, porque você se acha com um conhecimento pleno e absoluto sobre aquilo. Isso é uma falácia.

Felipe: a gente costuma dizer na Antropologia que aquilo que nos é familiar, nos é invisível. Por isso que o que é muito diferente da forma como a gente vive, a gente enxerga mais. Então por isso que o afastamento é importante.

Luma: o afastamento é importante para fazer uma análise crítica. Será que o que eu estou percebendo na pesquisa é de fato o que eu estava pensando das minhas hipóteses ou aquilo não tem nada a ver com aquilo que eu pensava? Eu posso ter surpresas, a gente pode ter surpresas. De repente, quem se coloca, às vezes, como travesti dentro de uma fala, e diz que é uma subversão; na prática, no estudo, na pesquisa em si, você pode perceber que aquele indivíduo, aquela indivídua, que se intitula daquela forma, não tem nada a ver com subversão, é um enquadramento.

Então tudo vai depender do contexto que você está analisando, entendeu? Então, não é pelo fato de eu ser travesti, que todas as questões sobre travesti, sou eu que tenho que falar. Até porque que contribuição nós diríamos que foi dada pelos que nos antecederam? Nós temos, por exemplo, vários pesquisadores/pesquisadoras como, por exemplo, Don Kulick. Grandes pesquisadores, que às vezes esquecemos até de lembrar. Certo que tem várias críticas, lógico. Mas eles fizeram um papel importante de registrar um estudo, uma análise, um estudo etnográfico de um determinado lugar, dentro de um contexto travesti.

Nós temos Larissa Pelúcio, Berenice Bento, Hélio Silva, este último um dos pioneiros. E às vezes esquecemos de trazer à tona essas pessoas que deram essa contribuição inicial. São importantes, e às vezes nem se identificam, nem são travestis, não têm nada a ver com essa questão. E nós fundamentamos muito de nossos trabalhos com seus resultados. Eu utilizei muito esses pesquisadores e essas pesquisadoras para fundamentar, às vezes para coadunar com a mesma ideia, e às vezes para refutar algumas formas de pensar. Por exemplo, o caso de como é percebido por alguns deles/as o lugar das pessoas travestis como sendo a grande metrópole. Como se a grande metrópole e o campo de prostituição fossem os únicos lugares de existência para essas pessoas. 
Lógico que eles/as poderiam ter a consciência que não era isso, mas o pensamento da sociedade era esse - o imaginário - do lugar da travesti. O que acabou sendo reforçado pelas produções, dado esse campo de estudos. E o que eu faço quando tenho conhecimento desses pensamentos, eu tenho acesso a esses teóricos? Eu passo a me autoperceber: olha, eu não sou da grande metrópole, eu não sou fruto da grande metrópole e nem da pista. Eu estou em um outro lugar, eu tenho outras técnicas de construção do corpo, e nem por isso eu deixo de ser como eu me autoidentifico, uma travesti. Eu não estou no mesmo lugar de trabalho, eu não estou no mesmo território geográfico da grande metrópole. Mas eu existo! E as pessoas não estão percebendo que existem outros lugares possíveis para as travestis. Não é desqualificando toda essa produção, porque ela é resultado de estudos em determinados campos de estudos.

Precisamos desmistificar essa ideia de uma generalização da travesti, como se o lugar da travesti fosse sempre a grande metrópole. Como se a travesti se construísse sempre na grande metrópole, como se as técnicas de construção de uma travesti fossem sempre as próteses e o silicone. E aquela lá do interior?

Felipe: Fazendo um gancho, nos fale um pouco do teu livro e das travestis com as quais você dialogou.

Luma: dialoguei com aquela travesti do interior que não teve acesso às técnicas de bombação, que não teve acesso às técnicas de silicone, que não teve acesso aos megahairs, às perucas; elas se construíram da forma e na possibilidade que tinham em termos de classe, mais uma vez, uma questão importante. Ser uma travesti numa grande metrópole é diferente de uma travesti que está no interior do interior, que não tem a pista como alternativa, onde não existem essas pistas. Elas são outras, de outra ordem, de outro contexto. Não têm as mesmas técnicas, não tem bombadeiras em muitos lugares, principalmente no passado não se tinha as bombadeiras e não se tinha essas técnicas. Mas se construía a travestilidade dentro do que era possível, e isso não é motivo de desqualificá-las. Mas de dizer que existem outras realidades. Outras realidades de resistência, de sobrevivência, que podem ter a mesma autodefinição travesti que das outras da grande metrópole. Então eu creio que, a partir daí, e das minhas interlocutoras no livro "Travestis na escola: assujeitamento e resistência à ordem normativa”, começo a fazer essa reflexão. Olha, naquela época já existiam travestis não só no interior, mas nas pequenas localidades...

Felipe: Fabiano Gontijo publicou um artigo intitulado "Ser Traveco é Melhor que Mulher: considerações preliminares acerca das discursividades do desenvolvimentismo e da heteronormatividade no mundo rural piauiense" (Bagoas, 2012), que fala sobre uma travesti que vive num assentamento do Movimento dos Trabalhadores Rurais Sem-Terra (MST), no interior do Piauí. 
Luma: sim, são possíveis essas existências. Mas quando se falava sobre isso, há algum tempo, não se entendia travesti com essas possibilidades. Quem traz à tona essas outras sujeitas são as novas produções, e eu venho nessa linha. Eu sou uma das primeiras a dizer "olha, mas existem outras". Não quero com isso desmerecer as meninas das pistas, até porque eu me identifico como travesti reconhecendo o trabalho e reconhecendo a resistência que elas fizeram historicamente. Mas preciso dizer que existem outras possibilidades, porque as próprias travestis, elas vão pensar que não tem outras possibilidades: ela abre um jornal, está lá; ela abre uma revista, está lá; ela lê um livro acadêmico, está lá, essa possibilidade única. Reproduzindo tudo isso, elas vão achar o quê? A única forma de sobrevivência vai ser eu ir para a capital, na grande metrópole, me construir com as técnicas que são necessárias, construir meu corpo e seguir meu caminho nessa linha. E aí você vê outras? Não. Estão lá sobrevivendo de outras formas, e o meu livro vai trazer muito disso. Tem travestis na escola também, tem aquela outra que está no doutorado fazendo uma tese. E eu vou trazer outras no livro. O trabalho aborda essas outras meninas do interior que estão na escola e sofrem diversas formas de resistência e de assujeitamento, se assujeitando muitas vezes, mas também produzindo resistências. E o meu lugar enquanto gestora foi importante na minha trajetória de vida, porque eu também fui professora, fui aluna na escola e fui gestora, coordenando 26 escolas distribuídas em 13 municípios do Ceará. E nessa vivência da gestão, coordenando escolas em municípios do interior, eu tive e utilizei essa possibilidade de acesso à essas meninas.

Felipe: e o que você achou, o que você encontrou?

Luma: encontrei coisas absurdas. Tinha hora que eu dizia "Nossa Senhora!". Então as meninas me procuravam, denunciavam na Coordenadoria Regional de Desenvolvimento da Educação (CREDE) da Secretaria Estadual de Educação, suas situações. Teve um caso que a gestora chamou os pais de um aluno para denunciar que o menino era afeminado, que o menino queria ser mulher, e pedia para o pai resolver o problema. E como se resolvia? Quando essa jovem, que seria uma trans, uma travesti, foi espancada, ela me procurou na CREDE. Fiquei chocada com a situação, e tive inicialmente que ter muita paciência, porque, muitas pessoas na escola não têm conhecimento, ou as vezes esquecem que existem normas sobre como lidar com as questões de gênero e diversidade sexual. A princípio, é necessário fazer as pessoas entenderem, então imediatamente eu fui para escola, levei a Constituição, levei o $\backslash$ Estatuto da Criança e do Adolescente (ECA) e promovi um debate na escola. E a diretora perguntou "mas por que você está trazendo isso, essas questões?", eu disse "para vocês entenderem que as pessoas não podem ser discriminadas por conta das suas singularidades". E aí eu expliquei o caso que tinha acontecido, que era inaceitável, porque a escola não tem esse papel de dizer como as pessoas devem se comportar ou não em termos de gênero e sexualidade. Elas têm livre espontaneidade de fazer o que elas desejam. Então foi um momento conflitante, mas que surtiu um efeito e uma mudança de postura. Esse garoto, que ainda era garoto na época da intervenção, passou a ter um outro tratamento na escola, a família passou a ter uma outra compreensão e ele se autoidentificou posteriormente como travesti. Passou a usar o nome, a usar o banheiro feminino e deste caso surgiram outras garotas na escola. Então elas encontraram uma liberdade de viver as suas singularidades de uma forma mais feliz e aberta, e respeitada. Então 
minha pesquisa começou assim, a partir de muitas situações que eu ficava sabendo e sempre intervinha.

Felipe: No teu livro, principalmente no último capítulo, tem algumas narrativas e descrições de situações, da formatura por exemplo, que são muito interessantes. Qual a sua avaliação do livro e quais os seus projetos futuros?

Luma: o livro já cumpriu um papel importante que é esse que eu acabei de falar: de mostrar que existem outras possibilidades de existência de travestis em outros lugares, principalmente no espaço escolar. Tinha que ter o viés, um foco; e o foco eram as travestis na escola, mas trouxe também o viés delas no interior, que era um outro olhar que tinha recebido atenção até então. Acho que o livro cumpre esse papel, traz muito a questão da dificuldade que é ser uma travesti que vive o espaço escolar. E muita gente que consegue ler o livro, começa a ter uma outra forma de pensar em relação à prática na escola, e muda suas práticas, porque começa a entender "nossa, como é difícil, né?", a pessoa não é aceita pelo nome que deseja, não pode utilizar o banheiro ao qual se identifica, enfim, não tem possibilidades outras como as demais têm. Não tem o mesmo direito à escola.

Felipe: isso não está resolvido, Luma, porque fui recentemente a Ouro Preto, na jornada do GEALI, no Instituto Federal de Ouro Preto e uma das grandes denúncias que me fizeram lá durante a jornada é que haviam muitos professores que não aceitavam usar o nome social, como se o respeito a esse direito fosse algo absurdo.

Luma: inclusive, assim, por isso que eu digo que ele cumpre esse papel de uma mudança de postura, de pensamento, traz uma outra forma de pensar, oxigenando ainda mais o pensamento sobre as travestis em um lugar que é a escola. Mas há essas resistências muito fortes: por exemplo, no Ceará, o livro teve grande importância para tomada de decisão do Conselho Estadual de Educação, que criou uma resolução exatamente para o nome social e sua utilização, o direito ao gênero ao qual se identifica. Então foi uma grande contribuição. Outros estados também, através da fundamentação teórica do livro, conseguem justificar e colocar a importância de aceitar as pessoas que se autoidentificam enquanto travestis ou transexuais, respeitando seu gênero. Esse é um papel importante, e continua muito atual, por conta dessas resistências: as pessoas conservadoras têm dificuldade e insistem em não querer aceitar - às vezes, elas até se aproximam das pessoas que vivenciam essa singularidade, mas não conseguem aceitar. Tem gente que não aceita, porque não teve a possibilidade de dialogar, não teve a oportunidade de ouvir, ou não se deu a oportunidade de ouvir ou ler o que vem sendo produzido. Quanto à questão do que há por vir em termos de pesquisa, eu estou constantemente em pesquisa, porque tenho projetos de pesquisas, assim como de extensão aprovados e com bolsistas.

Felipe: lembro-me de que uma de suas pesquisas atuais envolve um mapeamento de organizações no Ceará... 
Luma: sim, um mapeamento de organizações políticas LGBT no estado. Nós temos outro projeto sobre a questão dos homens trans, sobre o ambulatório transexualizador; tivemos o penúltimo agora com as pessoas trans e travestis nos presídios do Estado do Ceará. Então tem uma produção muito boa. Mas como todos/as docentes que estão na academia sabem, nós temos uma dinâmica de trabalho e, em particular, as figuras mais emblemáticas a nível nacional acabam tendo uma agenda muito cheia de compromissos, sendo muito solicitadas. E, às vezes, temos que entender a necessidade de contribuir com outras universidades que estão precisando ter alguém para apresentar estudos na área. Eu fui a primeira pessoa travesti a concluir um doutorado e ainda sou a única professora travesti concursada de uma Universidade Federal desse país. Assim, não é que seja uma carga, mas é uma responsabilidade muito grande. É necessário contribuir também com os/as outros/ as colegas, porque eu tenho uma consciência da importância de minha fala no processo de transformação do pensamento das pessoas, porque a minha própria presença já produz esse impacto: “como é uma travesti doutora?". Como ela fala, como ela se articula, como ela vai desenvolver suas ideias e começar a desmistificar o pensamento das pessoas que estão ouvindo, porque elas vão começar a dizer “será que estudou mesmo?", "será que tem conhecimento?", “será que produz algo novo, será que vem com alguma ideia nova?”, “o que vai fazer?”. Então, a própria presença produz um impacto pelo fato de responder tais indagações que sempre surgem.

Então, tenho uma agenda muito cheia de atividades, palestras, seminários, consultorias, parcerias, cursos com outros colegas. Temos muita produção, temos uma agenda apertada, temos que ensinar ainda, temos os projetos de pesquisa, os projetos de extensão. Tem essas palestras, essas atividades, que, inclusive, é um dos projetos de extensão, o Transformando. O Transformando já está na sua segunda versão do projeto de extensão, que são palestras desenvolvidas com meu aluno bolsista homem trans Kaio Lemos. Qual é a nossa missão no projeto? É exatamente disseminar esse conhecimento, desmistificando nossas singularidades. Então, eu que sou uma travesti e ele que é um homem trans, nós participamos de várias palestras, que somos convidados a dar, em escolas, universidades e outros lugares. Tudo isso faz parte do projeto Transformando, que, agora, para 2018, na sua segunda versão, tirou primeiro lugar na seleção da Pró-Reitoria de Extensão da UNILAB. Então isso demonstra o compromisso da produção em relação ao que está sendo feito. Já para uma nova publicação, com empenho e dedicação, tenho a ideia de trabalhar sobre travestis nas universidades.

Como é uma travesti na universidade? Mas não só como discente, trazendo a experiência de ser discente, docente e gestora, esses lugares em que já tive a oportunidade de estar. Qual é o lugar, que lugar é esse? Não para generalizar, mas para denunciar e tentar encontrar e trazer para a discussão elementos que não estão ainda em debate, que fazem parte de algo mais estrutural da universidade. Qual a dificuldade que nós temos de essa temática entrar, de ter abertura na universidade? O que é uma travesti dentro da universidade? Qual o lugar dessa sujeita nesse espaço? Porque as pessoas acham que é tranquilo: "ah, Luma, agora, é docente de uma universidade federal, ela não sofre preconceito". E é aí onde está, não é nada disso: nós temos resistências internas. A presença dessa 
travesti no corpo docente é uma afronta para muita gente. Então a gente precisa trazer outros saberes. Outra travesti não teve a oportunidade ainda - eu sou a primeira a vivenciar. Então eu estou sentindo a necessidade de - e já estou escrevendo alguma coisa relacionada a isso - falar sobre ser essa travesti nesse espaço. Ao mesmo tempo, tento desenvolver pesquisas e ensino que podem ser e estão sendo - utilizados para a produção de conhecimento como, por exemplo, para o estágio em gestão. Mas é algo proposital mesmo, para dizer às pessoas que nós temos outras capacidades que não só falar sobre gênero e sexualidades. A minha presença, ela já fala de gênero e sexualidade e, por isso, resolvi deixar a disciplina de Educação, Gênero e Sexualidade com outra colega do colegiado do curso de Pedagogia da UNILAB. Porque a minha presença nessa disciplina, que se julga não ter nada a ver, a minha presença já está fazendo um trabalho de gênero e sexualidades por si só. E eu vou ensinar o que eu aprendi, o meu conhecimento em relação à gestão em minha formação e experiência profissional. Então eu acho que é nessa linha que segue o ritmo da atuação da professora Luma na universidade. Nesse ano, tenho um desafio ainda maior, que é estar como presidenta da Associação Brasileira de Estudos da Homocultura (ABEH).

Felipe: você está presidenta da Associação Brasileira de Estudos da Homocultura (ABEH) e você tem uma experiência enorme com participação em gestão, liderança de grupo de pesquisa, secretaria e enfim. Eu gostaria de saber quais as suas expectativas para todos os projetos que você tem apresentado para a ABEH. A Revista Brasileira de Estudos da Homocultura (REBEH) é um projeto editorial novo que vai ter quatro números por ano, que você está encabeçando com Bruna Andrade Irineu, da Universidade Federal do Tocantins, um conselho editorial poderoso.

Luma: com seu apoio.

Felipe: eu estou aqui na primeira entrevista, estou muito feliz, é um prazer enorme. Além disso, você também está propondo em sua gestão um prêmio de dissertações e teses que vai premiar as melhores teses em Estudos da Homocultura, um congresso potente, e muito mais. Eu acho que não só o fato de você ser uma pessoa trans*, mas de você ter competências que te levam para esse lugar - o Conselho Nacional de Combate à Discriminação LGBT (CNCD), por exemplo, você tem um assento lá. Queria que você falasse um pouco desse lugar de Presidenta da ABEH.

Luma: é super desafiador e necessita uma dedicação de tempo e de saberes para conduzir o processo, mas como eu tenho essa formação em gestão, ela me ajuda muito, principalmente numa gestão democrática. Então, a diretoria da ABEH está toda em comunicação através do WhatsApp. São pessoas de diversos lugares do país, doutores, professores de diversas universidades; mas nós estamos juntos. E todas as decisões são deliberadas a partir do grupo. Isso é muito enriquecedor, é uma prática que me disseram ser algo que não ocorria nas gestões anteriores, por conta da dificuldade de comunicação. Então nós estamos num período da história que facilita muito, pois as tecnologias contribuem bastante. Antes, os parceiros, os colegas, que antecederam talvez não tinham a possibilidade dessas tecnologias. 
Nós estamos utilizando a tecnologia da melhor forma possível para produzir um trabalho cada vez melhor, porque nós sempre tivemos gestões excelentes na $\mathrm{ABEH}$ e nós não podemos diminuir essa qualidade. A ideia é essa: potencializar, fazer o melhor e que a $\mathrm{ABEH}$ não seja vista apenas como um congresso internacional, ela seja vista de fato como uma associação científica que tem uma gestão e que tem que atuar todos os dias, no período dessa gestão. Nós temos vários dispositivos de trabalho, que, no caso, é um assento no CNCD - que é um conselho que discute as questões LGBT, que produz resoluções importantes, como a do nome social. Então tem um papel muito importante. E nós conseguimos, novamente, uma vaga para a associação, o que não é fácil. Existe um edital que traz o número de vagas que são necessárias, e só tem uma vaga para associações com produção de conhecimento. Por sorte, no Brasil, nós só temos a ABEH, especificamente, e o que acontece? Tem a questão burocrática, nós fizemos a parte burocrática, atendemos. E novamente agora, nessa nova gestão 2018-2019, nós temos um assento. E eu fiz questão, desde que assumi a ABEH, de participar das reuniões, como uma forma de interagir mais, uma forma de estar presente, de conhecer mais essa sistemática de trabalho e de socializar esse conhecimento com os demais que fazem parte da Associação, principalmente a diretoria, com quem tenho contato mais direto. Mas a gente também leva essas informações para os meios de comunicação - o site, nas redes sociais, enfim -, tentamos socializar os acontecimentos.

É importante a ABEH estar no referido conselho, porque possibilita a comunicação com diversas instituições governamentais e não-governamentais, produz uma abertura muito grande. Eu estive como presidente na Câmara de Legislação e Normas do conselho em questão na gestão anterior. E estamos tentando produzir outras mudanças na $\mathrm{ABEH}$ : ter mais espaço, que é uma forma de ter acesso para poder contribuir, inclusive chegando até à Capes. É uma forma também de chegar mais próximo da Capes e do CNPq, para tentar produzir abertura nesse sistema de ciência e tecnologia fechado, em que não há ainda uma subárea específica na grande área interdisciplinar para tratar de gênero e diversidade sexual. Nem na avaliação da Pós-Graduação, nem no fomento à pesquisa. Então, nós precisamos tentar buscar uma abertura no que nos interessa, também, e não ficarmos sendo avaliados por pessoas que não tenham a qualificação, um conhecimento específico nessa área, e acabam desvirtuando ou deturpando tudo o que produzimos. Ou então tendo nossas produções desqualificadas enquanto pesquisa. Eu vejo o conselho como uma das alternativas de se aproximar para produzir essas mudanças. Outra questão importante é, na atuação interna, tentar produzir outros mecanismos, ou seja, aumentar a produção. Por que esperar de dois em dois anos para produzir e difundir conhecimento em um congresso, se os processos de mudança são rápidos, as coisas mudam com uma velocidade imensa? Precisamos intensificar nossos canais de diálogo e difusão do conhecimento E como fazer isso? Criar a revista da $\mathrm{ABEH}$, que se chama Rebeh, Revista Brasileira de Estudos da Homocultura.

Às vezes as pessoas questionam “ah, porque a $\mathrm{ABEH}$ não muda, na sua gestão, o nome?”. Mas precisamos entender que existe uma construção histórica. Esse nome foi construído desde o início da $\mathrm{ABEH}$, em 2001, pois era o termo que dava conta, na época, da realidade da diversidade sexual. 
O tempo vai passando e as coisas vão mudando. Ou seja, a gente vai mudar agora, e mais lá na frente vai ter que mudar de novo, porque as coisas não vão se engessar. O importante é produzir conhecimento que traga o que a gente entende de diferença na atualidade e os devires dessa diferença. O nome da associação não é o central, mas a sua produção. Desde as gestões anteriores, a $\mathrm{ABEH}$ tem uma grande produtividade que dá conta desses devires - cada um no seu tempo e cada um dentro das suas possibilidades.

Outra necessidade que vejo é a de incentivar as produções em gênero e sexualidades. Nós presenciamos tantos prêmios, tantas menções honrosas, enfim, para produções de diversas áreas; então por que não incentivarmos a produção criando uma premiação através da $\mathrm{ABEH}$ - que seja feita no Congresso Internacional da ABEH, que é o CINABEH, no caso o IX CINABEH? Isso vai possibilitar premiar as dissertações e as teses num período de dois anos, nessa primeira edição, de 2016 a 2017. Por que não fazer isso, já que nós temos conhecimento que existem várias produções de dissertações e teses nessa área? Eu vejo isso como um motivador para as produções, como uma forma também de atuação dinâmica para a $\mathrm{ABEH}$. Para isso, a $\mathrm{ABEH}$ procura parcerias, a $\mathrm{ABEH} e$ nós começamos pelo nosso estado. O ideal é que onde a ABEH passe, ela possibilite, a nível estadual, uma agregação de pesquisadores e pesquisadoras em gênero e diversidade sexual. Porque só a nossa união é que vai garantir uma mudança no que temos hoje, porque se nós continuarmos cada um em sua caixinha, dispersos, nós não vamos conseguir criar uma linha de frente forte dentro dessas resistências que estamos vivenciando hoje. Então no Ceará, já está sendo efetivada uma rede, nós já temos uma rede de pesquisadores e pesquisadoras em gênero e diversidade sexual, com um ou dois representantes em cada universidade do estado. Nós estamos montando um calendário de atividades até o IX CINABEH. Então teremos atividades no decorrer do ano de 2018, na URCA, Universidade Regional do Cariri, na UVA, Universidade do Vale do Acaraú, na UECE, Universidade Estadual do Ceará, na UFC, Universidade Federal do Ceará e na UNILAB.

Felipe: eu soube que na UNILAB aqui da Bahia vai ter também alguma atividade.

Luma: isso. Nós estamos pretendendo também fazer uma atividade, um Pré-ABEH, aqui em São Francisco do Conde, na UNILAB. É outra intenção como forma de agregar também pesquisadores e pesquisadoras da Bahia. É uma atividade árdua e difícil, porque, primeiro, nós não temos recurso. Porque se nós tivéssemos recursos, poderíamos fazer um movimento nacional, onde poderíamos articular por estado e, depois de articulado por estado - todo o Brasil já articulado, das universidades estaduais e federais, públicas, com a possibilidade de particulares, se tivessem interesse, porque temos pesquisadores e pesquisadoras bons que estão nas universidades privadas - organizados para que, posteriormente, tenhamos essa cadeia muito mais ampla. Dentro das condições que temos, o dever será primeiro de casa, temos que nos organizar estadualmente e, depois de organizados em termos de estado, possibilitar ter essa rede mais geral. E aí eu creio que conseguiríamos potencializar os nossos trabalhos ainda mais e criar uma frente ainda mais forte. Esse é o meu 
desejo. Estou tentando produzir isso agora no estado do Ceará e estou colaborando com isso, na medida do possível, nos outros estados.

Felipe: mas fica o convite para todos irem ao Ceará em novembro de 2018, né?

Luma: todos/as pesquisadores/as no Ceará em novembro de 2018, de 28 a 30, no IX CINABEH, em que a temática será "Diversidade Sexual, Gênero e Raça: Diálogos Brasil-África". Queremos promover outra perspectiva epistemológica dos saberes, em que nós iremos trazer uma proposta mais Sul-Sul de conhecimento, de produção, que vai dialogar com as formas que estão muito presentes, num pensamento eurocêntrico, que vai entrar em debate. Vamos produzir diálogos importantes. Mas trazendo um viés muito forte desse pensamento que, às vezes, não é considerado, que é o pensamento da diferença em si, interseccionalizando as questões LGBT com as questões raciais. E que acaba intersecionalizando também com as questões de classe, pois não tem como falar de LGBT, de negro e não tratar disso. Então será um momento de aprendizagem, onde nós iremos trazer teóricos e teóricas de fora do país que são considerados/as relevantes, com produções relevantes na temática, e também os brasileiros que têm reconhecido trabalho/produção nessa área. Nós iremos ter a possibilidade de dialogar e também apresentar nossas produções. Que as pessoas consigam e se desafiem a produzir algo que venha ao encontro dessa temática e que consiga contribuir com o conhecimento em pauta. Nós precisamos nos alinhar, nos unir e trazer essas questões interseccionalizadas, o que vai abrir um debate de possibilidades e de alianças que são fundamentais para a nossa resistência e enfrentamento. Não só resistência, mas também enfrentamento. Então a ABEH vem com essa cara e esse desafio. E esse desafio vai passar para a próxima gestão; e que outra gestão traga novos desafios para nosso crescimento.

Felipe: Luma, eu gostaria de dizer que estou muito emocionado de ter tido a oportunidade de te entrevistar para o primeiro número da Rebeh, com uma temática que é a visibilidade trans. Eu sei que, hoje em dia, nesses lugares de fala, quem pode falar o quê, eu me sinto enquanto um - eu não gosto de dizer que eu sou homem - gay, um viado. Desse lugar, participar desse número da Rebeh é uma grande honra. Eu tenho um prazer enorme em pensar projetos editoriais mais inclusivos, e você e Bruna Andrade Irineu têm produzido seções maravilhosas, que incorporam as diferentes áreas do conhecimento e um viés interdisciplinar. Então eu desejo todo o sucesso para a Rebeh. Mas antes de terminar essa entrevista, o que é hoje a visibilidade trans*? Eu queria que de forma bem curtinha, você mandasse uma mensagem para todas as pesquisadoras e pesquisadores trans* do Brasil. Que você mandasse uma mensagem não teórica, não política, mas uma mensagem de afeto.

Luma: hoje, é difícil até falar sobre uma visibilidade trans. Como tratar de uma visibilidade trans em corpos que são tão diferentes? Eu acho que temos que dar a visibilidade para o que é vulnerabilizado, eu acho que pensar pessoas trans seria pensar um corpo vulnerável, um corpo que não se enquadra, um corpo que é maldito. E aí, sim, eu consigo pensar numa possibilidade dessa visibilidade, uma visibilidade que possibilite uma reflexão nestes corpos. E aí para algumas que 
definem de um jeito engessado e para outras que definem de outro jeito engessado talvez não consigam compreender o que defendi aqui. Porque o que importa não é se o corpo é trans ou travesti, o que esse corpo é; o que importa é que tipo de sofrimento a pessoa passa por não ter um corpo que se enquadre às normas hegemônicas da sociedade tradicional. Então qualquer que seja o corpo, ele tem que ter uma visibilidade num sentido de um processo de mudança de pensamento, modificar a forma de pensar sobre aquele corpo. E aí entra o viés dos corpos diversos que tem uma interseccionalidade com a questão de gênero e sexualidade. Assim, por que não modificar, por que não ter outras perspectivas para esses corpos? Por que pensar de forma negativa? Por que achar que esses corpos não podem ocupar lugares de tomada de decisões importantes? O que vem muito pelo viés da nova onda do feminismo por representatividade.

Temos que ter um cuidado: não basta representatividade. Ela, por si só, não nos representa, e talvez por isso que eu achei interessante ser entrevistada por uma pessoa que não é trans. Até para as pessoas entenderem que é possível alguém que não é trans ou travesti ter um conhecimento e uma visão política qualificada em termos de conhecer essa realidade do que mesmo alguém que vivencia, porque não é uma questão de essencialismo. Por exemplo, não é porque você é negro, que você conhece todo o contexto histórico do que foi vivenciado e do que existiu com o negro e a negra no Brasil. Nós podemos ter, inclusive, e nós temos, gays e lésbicas que reproduzem a transfobia. Então não é uma questão de essencialismo. Não é porque se é algo, que já se nasce sabendo de tudo. E tem gente que acha que é assim, é travesti, se disser isso, então é a verdade plena absoluta; se é negro, então já sabe de tudo, se é mulher... Mas não é dessa ordem, não é uma questão de essência, é uma questão de conhecimento político da realidade. Por isso, a importância de alguém que não é travesti estar me entrevistando - mas é alguém solidário e que tem conhecimento sobre essa trajetória, história, e até aproximação com as pesquisas, com os estudos que realizam. Ao você fazer uma pesquisa, você vivencia aquele universo, você passa a entendê-lo e com análise crítica. Então, assim, tem o cuidado com essa questão. Não é pelo fato de ser uma travesti que se sabe tudo sobre travesti. Podemos ter travestis e transexuais que são LGBTfóbicas. Então não é uma questão de ser isso ou ser aquilo. Nós precisamos de representatividades, mas de representatividades que tenham consciência política, que tenham conhecimento histórico, que tenham o conhecimento também de vivência; mas que tenham essa consciência política, isso não só para travestis, mas para negros, para mulheres. Precisamos de representatividade, precisamos ocupar espaços, mas precisamos ter consciência política, disso não pode se esquecer, isso é importante.

Em relação à mensagem que é necessário emitir às colegas: é dizer que estamos vivendo num momento muito difícil, um momento de retrocesso no pouco que conquistamos. Como diria Berenice Bento, as gambiarras que conquistamos, mesmo sendo ainda muito simbólicas e poucas, não atendem ao que realmente precisamos; esse pouco que conquistamos, essas gambiarras conquistadas, elas estão por si só, na conjuntura atual do país, ameaçadas. E aí, o que eu queria dizer para as colegas, a mensagem afetiva, é primeiro dizer que elas não estão sós, eu também estou com elas e outras Lumas, e outras trans, e outras travestis, outras pessoas héteros, gays, lésbicas e 
bissexuais que estão solidárias à nossa vivência, elas também estão do nosso lado. Sabemos que tem pessoas que não aceitam a nossa existência, mas nas diversas formas de ser, em termos de identidade sexual, nós vamos encontrar pessoas que vão nos ajudar a abrir portas e a resistir, e ainda produzir enfrentamentos. Que seja permitido também que essas pessoas se aproximem de todas nós e se juntem para podermos seguir, porque se continuar da forma que está serão momentos difíceis, de caça mesmo, e nada é garantido. Portanto, o que nos resta é a resistência e os enfrentamentos e buscar a solidariedade, encontrar as pessoas solidárias - não espantar as pessoas que podem nos ajudar por conta disso, por conta dessa diferença, por conta de não ser igual, mas buscar aliados e produzir alianças para superar as dificuldades que estamos passando e que ainda iremos passar. É difícil, mas é possível. Eu sou um exemplo vivo disso, é difícil chegar aonde cheguei, é difícil chegar aonde a outra chegou como advogada, como médica, sendo travesti, mas é possível. Vamos encontrar dificuldades, mas vamos também encontrar aberturas e aliados. São as frestas, que a gente deve aproveitar para abrir espaços, não só para nós, mas para quem virá nesse processo de construção de aberturas.

Recebido em: 15/01/2018

Aceito em: 18/01/2018 